ШОГЕНОВ БЕТАЛ АМИНОВИЧ д. э. н., профессор ФОГБОУ ВО «Кабардино-Балкарский государственный аграрный университет», e-mail: betal01@mail.ru

ШАКОВА ФАТИМА МУРАДИНОВНА

к. э. н., дочент ФГГБОУ ВО

«Северо-Кавказская государственная академия»,

e-mail:shakovaf@mail.ru

\title{
РЫНОЧНАЯ ИНФРАСТРУКТУРА РЕГИОНА: ВЧЕРА, СЕГОАНЯ, ЗАВТРА
}

Аннотауия. Цель работы. В статье предполагается рассмотреть прочессы формирования и становления, особенности функиионирования и перспективы развития рыночной инфраструктуры в регионах $О Ф$ как иелепологающей деятельности государства и его субъектов в деле активизачии рыночных процессов на территориях. Методология проведения исследования. Использованы общенаучные приемы и методы эмпирического исследования, сравнительный и системный анализ теоретического и практического материала. Результаты работы. В прочессе исследования понятия рыночной инфраструктуры региона автор определяет ее как совокупность общих условий функиионирования регионального рынка. При этом диспропориии регионального экономического развития в

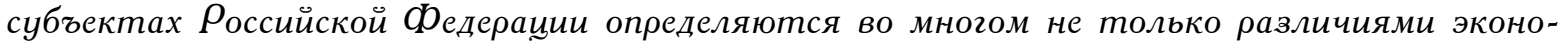
мического потенциала территорий, но и неразвитостью их рыночных инфраструктур. Область применения результатов. Проведенный анализ методов регулирования рыноч-

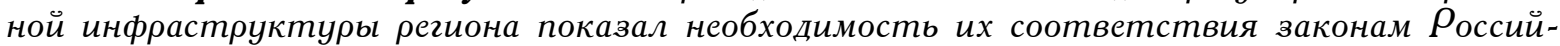
ской С едерации и то, что они должны быть основой региональных долгосрочных прогнозов и стратегии соииально-экономического развития, целевых региональных программ,

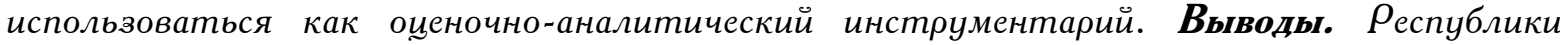
СКСDО характеризуются определенной степенью уникальности (наряду с общими параметрами развития), т. е. системой факторов и условий, присущих, как любой региональной системе, именно им. С учетом таких факторов на уровне республик СКФОО иелесообразно разработать и принять местные правовые положения (соответствующие законам $Р Ф D)$, которые обеспечивали бы формирование механизма взаимодействия субъектов рыночной инфраструктуры, то есть создание из имеющихся отдельных элементов правового механизма единой системы управления в регионе.

Ключевые слова: рыночная инфраструктура, принципы, механизмы и методы регулирования рыночной инфраструктуры региона.

ALKL YCHEV ALKLYCH MAGOMEDOVICH doctor of Economics, $\rho_{\text {rofessor, Institute }}$ of Economics and Finance Chechen state University, e-mail: akulich@mail.ru

SHOGENOV BETAL AMINOVICH doctor of Economics, $P_{\text {rofessor of Kabardino-Balkar }}$ STATE UNIVERSITY state agrarian University", e-mail:betal01@mail.ru 
SHAKOVA FATIMA MURADINOVNA

Ph. D. in Economics, associate Professor

North Caucasus state Academy,

e-mail:shakovaf@mail.ru

\section{MARKET INFRASTRUCTURE OF THE REGION: YESTERDAY, TODAY, TOMORROW}

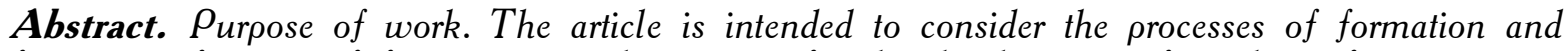
formation, features of functioning and prospects for the development of market infrastructure in the regions of the Russian Federation as a goal-oriented activity of the state and its subjects in the activation of market processes in the territories. Methodology of the study. General scientific methods and methods of empirical research, comparative and systematic analysis of theoretical and practical material are used. Result of work. In the process of studying the concept of market infrastructure of the region, the author defines it as a set of General conditions for the functioning of the regional market. At the same time, regional economic development imbalances in the Russian Federation's constituent entities are largely determined not only by differences in the economic potential of the territories, but also by the underdevelopment of their market infrastructures. Scope of the results. The analysis of methods of regulating the market infrastructure of the region has shown the need for their compliance with the laws of the Russian Federation and that they should be the basis of regional long-term forecasts and strategies for socio-economic development, targeted regional programs, and used as an evaluation and analytical tool. Conclusions. The republics of the North Caucasus Federal district are characterized by a certain degree of uniqueness (along with the General parameters of development), i.e. a system of factors and conditions inherent in them, as in any regional system. Taking into account such factors at the level of the republics of the North Caucasus Federal district should develop and adopt a local legal provisions (relevant to the laws of the Russian Federation), which would ensure the formation of the mechanism of interaction of subjects of market infrastructure, the establishment of the existing separate elements of the legal mechanism for unified control system in the region. Keywords: market infrastructure, principles, mechanisms and methods of regulating the market infrastructure of

Введение. Для нормального развития всех отраслей рыночной экономики нужны определенные внешние условия, составляющие вспомогательные функции в общественном воспроизводстве [2].

Дальнейшее расширение его масштабов происходит в ходе выделения производства услуг в специализированные формы. Отрасли инфраструктуры производят услуги, а не материальную продукцию, поэтому, по мнению некоторых авторов, инфраструктура представляет собой часть сферы услуг. Однако другие исследователи предлагают рассматривать инфраструктуру как «каркас» и «фундамент» экономики [6].

Различные подсистемы инфраструктуры не существует обособленно друг от друга, они переплетаются, взаимодействуют и взаимодополняют друг друга, выделяя тем самым инфраструктуру в самостоятельную сферу экономики [1]. Стихийно создаваемая в России рыночная инфраструктура лишь частично отражает потребности субъектов рыночных отношений и нуждается в теоретическом осмыслении и практических рекомендациях по ее совершенствованию, что позволяет прогнозировать ее дальнейшее развитие [11].

Вопрос о необходимости выделения рыночной инфраструктуры в относительно самостоятельную подсистему экономики стал рассматриваться в западной литературе еще во время экономического кризиса 70-х годов XIX века. Тогда особо остро прозвучала проблема несоответствия системы рыночного обращения товаров потребностям сбыта продукции [15].

Особенностью настоящего исследования является определение понятия «рыночная инфраструктура», основных принципов ее формирования и ее основных функций на современном этапе развития экономики регионов РФ. По нашему мнению, рыночную инфраструктуру можно представить как совокупность рыночных институтов, обеспечивающих взаимодействие и наличие «обратной связи» между производством и потреблением и способствующих устойчивому развитию системы рынков [12]. Под рыночными институтами в данном определении 
следует понимать не только правила, по которым хозяйствующие субъекты взаимодействуют друг с другом и осуществляют экономическую деятельность, но и совокупность организаций, которые формально реализуют на практике эти правила и процедуры поведения.

Методология проведения исследования. Сегодня можно выделить понятие рыночной инфраструктуры как совокупности общих условий функционирования рынка.

Для отечественной экономической литературы понятие рыночная инфраструктуры начинается со времен зарождения в Российской Федерации рыночных отношений, т. к. в существовавшей долгое время в СССР административно-бюрократической системе хозяйствования функции рыночной инфраструктуры выполнялись с помощью таких распределительных органов, как Госплан, Госснаб, отраслевые министерства и ведомства и их подразделений.

С начала 90-х годов появилось множество работ отечественных авторов, посвященных исследованию сущности понятия рыночной инфраструктуры. В общем потоке всех определений рыночной инфраструктуры, на наш взгляд, можно выделить три основных направления.

Первое направление рассматривает рыночную инфраструктуру как совокупность отраслей и сфер деятельности и базируется на распределительной концепции, при которой она определяется как «организационно-экономическая система, обеспечивающая свободный перелив и обмен различного рода ресурсов: товарных, сырьевых, финансовых, трудовых, интеллектуальных, информационных, на основе которых возможно функционирование экономически эффективной хозяйственной системы в целом или ее отдельных частей» (Е. Б. Муханова) [16].

Второе направление под рыночной инфраструктурой понимает совокупность предприятий, учреждений и организаций, обеспечивающую эффективное взаимодействие между основными субъектами рыночных отношений - продавцами и покупателями (институциональная концепция - Р. Г. Маниловский и др.) [8].

Третья группа определяет рыночную инфраструктуру как обеспечивающую рыночные процессы совокупность технических средств и оборудования (логистическая концепция - И. К. Белявский [7], В. Е. Маневич, В. И. Одесс, Л. А. Селезнева [14], Г. П. Журавлева [10] и др.).

Некоторые авторы дополняют этот состав также системой органов государственного регулирования экономики или же элементами социальной инфраструктуры (Е. Б. Муханова) [16].

Такое множество определений предмета и состава рыночной инфраструктуры объясняется отсутствием единого методологического аппарата исследования данного понятия, а также слабой развитостью институциональной и законодательной баз рыночной инфраструктуры [18].

Результаты. Анализ концепций различных авторов позволяет в наиболее общем виде представить рыночную инфраструктуру как сложную организационно-экономическую систему, состоящую из следующих основных элементов (см. рис.1).

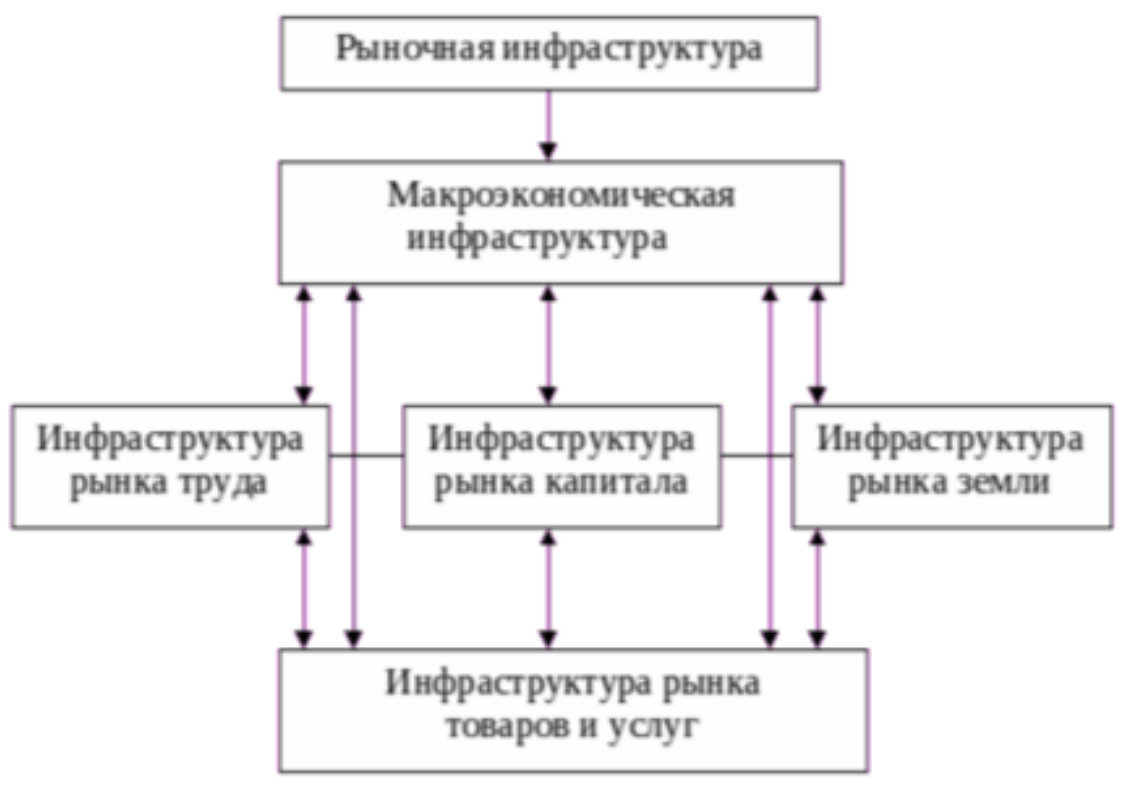

Рис. 1. Рыночная инфраструктура. 
Некоторые исследователи в своих работах часто идентифицируют понятия «рыночная инфраструктура» и «инфраструктура рынка». При этом категория «инфраструктура рынка» подразумевает наличие институтов, обслуживающих отдельные виды рынков или же экономические отношения, складывающиеся на определенном типе рынка (продуктовые рынки, финансовые рынки, рынки труда и т. д.). В этом случае рынок понимается как обособленная экономическая система, и поэтому понятие инфраструктура рынка может рассматриваться как часть понятия «рыночная инфраструктура».

Понятие же «рыночная инфраструктура» намного шире и включает в себя все связи и отношения между элементами экономической системы, основанные на рыночных принципах. Исходя из этого, на наш взгляд, рыночную инфраструктуру можно представить как совокупность рыночных институтов, обеспечивающих взаимодействие и наличие «обратной связи» между производством и потреблением и способствующих устойчивому развитию системы рынков. Под рыночными институтами в данном определении следует понимать не только правила, по которым хозяйствующие субъекты взаимодействуют друг с другом и осуществляют экономическую деятельность, но и совокупность организаций, которые формально реализуют на практике эти правила и процедуры поведения [19].

Таким образом, в ответ на общественную потребность в каком-либо институте экономические агенты обязательно создают такой институт, причем без какого-то ни было принуждения [12].

С другой стороны, государство должно санкционировать социально целесообразные самовозникающие институты путем создания соответствующей законодательной базы и контроля за соблюдением законов.

Одним из важнейших факторов формирования рыночной инфраструктуры является ее институциональная база, адекватная уровню развития производства и хозяйственных связей [17].

Специфической чертой становления рыночной инфраструктуры в нашей стране является ее функционирование параллельно с централизованной системой инфраструктуры. Поэтому институциональное и законодательное оформление инфраструктуры рынка должно было содействовать свободному выбору потребителей, а также обеспечению равных прав всем [5].

В экономической литературе под «институтом» подразумевают совокупность общепринятых правил и традиций, в рамках которых хозяйствующие субъекты осуществляют свою деятельность и взаимодействуют друг с другом. В более широком смысле в это понятие включают и специализированные организации, которые формально реализуют эти правила [20]. В плановой экономике, для которой была свойственна директивная форма связи производства и потребления, роль таких институтов инфраструктуры выполняли министерства и ведомства, а также централизованные и местные органы Госплана и Госснаба. Их решения имели силу закона для нижестоящих и подчиненных им хозяйственных звеньев. Действуя довольно длительное время, эта система обусловила ряд трудностей становления и развития новых институтов при переходе экономики страны к рыночным отношениям. Поэтому в качестве первоочередной задачи необходимым представлялось осуществить коренную перестройку действующих организаций и предприятий систем Госснаба, Госплана, министерств и ведомств. Одновременно весьма важной задачей являлось формирование и развитие в сфере товарного обращения принципиально новых институтов, отвечающих требованиям становления цивилизованных основ рыночной системы распределения продукции. Имеется в виду создание разветвленной сети рыночных институтов, выполняющих оптово-посреднические, финансовокредитные, информационно-рекламные, торговые и другие услуги, способствующие продвижению продукции от товаропроизводителей к конечному потребителю.

Область применения результатов. Формирование институциональной базы рыночной инфраструктуры невозможно без принятия соответствующих законодательных основ перехода к рынку и создания имманентной ему инфраструктуры. Так в 1990 году с принятием законов «О центральном банке Российской Федерации» и «О банках и банковской деятельности» (в 1995 и 1996 годах эти законы были приняты в новой уточненной редакции) были созданы законодательные основы функционирования современной банковской системы России. Банки были объявлены экономически самостоятельными учреждениями, имеющими право осуществлять установленные законом банковские операции. 
Устранение негативных последствий от деградации институциональных структур (бывших систем Госснаба, министерств и ведомств, государственной и кооперативной торговли), допущенных в результате самоустранения государства от процессов приватизации и акционирования в сфере обращения, было возможно прежде всего усилением роли государства в структурных преобразованиях экономики. В частности, разработке программы перехода к рыночному распределению общественной продукции, в развитии действующих и формировании новых элементов и блоков рыночной инфраструктуры [9]. Поэтому были внесены необходимые изменения в соответствующие законодательные акты, приняты новые законоположения, регламентирующие государственный подход к формированию институциональных предпосылок в деле формирования цивилизованной рыночной инфраструктуры.

При регулировании этих изменений использовалась система экономических и административных методов управления развитием рыночной инфраструктуры [13].

Органами же государственного управления и регулирования выступили отделы аппарата региональных администраций, территориальные управления министерств и ведомств, различные комитеты и департаменты, государственные финансово-кредитные органы, налоговые управления и инспекции и др.

В современных условиях региональные администрации при воздействии на субъекты рыночной инфраструктуры основной упор пытаются делать преимущественно на экономические методы. Экономические методы в отличие от административных оказывают косвенное воздействие на объекты управления, предполагая полную самостоятельность и ответственность хозяйствующих субъектов. Через экономические методы, связанные с налогообложением, кредитом, централизованными инвестициями, субвенциями и др., создаются механизмы ориентации субъектов рыночной инфраструктуры на эффективный режим функционирования регионального воспроизводства [3].

Выводы. Говоря об использовании административных и экономических методов регулирования рыночной инфраструктуры, необходимо рассмотреть вопросы правовой регламентации этого воздействия.

Во-первых, это законодательные акты, которые регламентируют деятельность субъектов рыночной инфраструктуры. Например, Федеральный закон «О банках и банковской деятельности», «О Центральном банке Российской Федерации», «О товарных биржах и биржевой торговле».

Во-вторых, это законы, касающиеся условий формирования и развития рыночной инфраструктуры, устанавливающие налоговый режим, антимонопольное законодательство.

Другим существенным элементом правовой базы функционирования рыночной инфраструктуры являются законодательные акты субъектов Российской Федерации, регулирующие этот процесс на уровне региона.

Если говорить о законотворческой деятельности на уровне такого субъекта СКФО, как, к примеру, Чеченская Республика, то она имеет тот принципиальный недостаток, что принятие соответствующих нормативных актов, регулирующих процессы формирования и развития республиканской рыночной инфраструктуры, идет крайне медленно и неравномерно. Одной из основных причин неразработанности законодательства является, на наш взгляд, то, что сами региональные рынки слаборазвиты и характеризуются неразвитостью инфраструктуры и коммуникаций, поэтому если о федеральной системе регулирования рыночной инфраструктуры можно сказать как о сложившейся, то говорить о регулировании на республиканском уровне пока рано. При принятии решений республиканские власти руководствуются преимущественно федеральными законоположениями. Однако Чеченская Республика характеризуется определенной степенью уникальности (наряду с общими параметрами развития), т. е. системой факторов и условий, присущих, как любой региональной системе, именно ей. С учетом таких факторов на уровне республики целесообразно разработать и принять местные правовые положения (соответствующие законам РФ), которые обеспечивали бы:

- формирование конкурентной среды на региональных рынках;

- развитие специализированной инфраструктуры различных типов республиканских рынков;

- создание механизма взаимодействия субъектов рыночной инфраструктуры: торгово- 
посреднических, финансово-кредитных и др. организаций республики на основе согласования их экономических интересов.

Одной из главных задач регулирования на современном этапе является создание из имеющихся отдельных элементов правового механизма единой системы управления в регионе [4].

Помимо сочетания административных и экономических методов регулирования, для эффективного управления процессом функционирования рыночной инфраструктуры Чеченской Республики, как и другим субъектам СКФО, нужна адекватная материально-техническая и финансово-экономическая базы.

Литература

1. Абаев А. В. Влияние инфраструктуры на экономический рост в регионе // Развитие экономики и бизнеса: сб. науч. тр. / под ред А Ф. Шуплецова. - Иркутск: Изд-во БГУЭП, 2011. - 173 с.

2. Алклычев А. М. Управление прочессом развития рыночной инфраструктуры товарного рынка: региональный аспект // Конкурентоспособность регионов. Стратегия устойчивого развития: III Межд. научно-практическая конф. 2017. (Псков, 25-27 октября 2017 г.). Псков: Изд-во Псковского государственного университета, 2017. - С. 61-69.

3. Алклычев А. М. Инновационная политика регионов Российской Федераџии в целях привлечения инвестиций и возможности ее реализации // Региональная экономика: теория и практика. - 2014. - № 3 (330). - C. 2-9.

4. Алклычев А. М. Инвестиционный механизм финансирования сельскохозяйственных предприятий 6 регионе // Региональные проблемы преобразования экономики. - 2015. - № 12 (62). - С. 15-22.

5. Андреева О. Р. К вопросу о динамике элементного состава инфраструктуры // Актуальные проблемы современного хозяйственного развития: воспроизводственный аспект: сб. науч. тр. / Под ред. Б. Д. Бабаева. - Иваново: Иван.гос. ун-т, 2010. - 472 с.

6. Ахтариева Л. Г. Системная модернизация региональной рыночной инфраструктуры // Проблемы современной экономики. - 2008. - № 3 (27). - С. 388-393.

7. Беляевский И. К. Маркетинговые исследования: Учебное пособие / Московский государственный университет экономики, статистики и информатики. - М. 2004. - 414 c.

8. Бизнес-план. Под. ред. Р. Г. Маниловского. - М. Финансы и статистика. 2002. - 160 с.

9. Дохолян С. В., Вартанова М. Л. Концептуальные основы эффективного функционирования инфраструктуры продовольственного рынка региона // Российское предпринимательство. - 2017. - № 10. Том 18. - C. 1523-1546.

10. Журавлева Г. П. Экономическая теория. Микроэкономика - 1, 2: Учебник / Под общ. ред. заслуженного деятеля науки РФ, проф., д-ра экон. наук Г. П. Журавлевой. - 6-е изд., испр. и доп. - М.: Издательско-торговая корпорачия «Дашков и $K^{\circ} », 2014 .-934$ с.

11. Зоидов К. Х., Алклычев А. М. Управление прочессом развития рыночной инфраструктуры товарного рынка региона // Финансовые механизмы аџиклического регулирования структурных диспропориий в экономике России и других стран СНГ: межд. научно-практическая конф. 2017. (Москва, 26-27 февраля 2017 г.). - М.: Изд-во Института проблем рынка РАН, 2017. - С. 132-138.

12. Идзиев Г. И. Региональные особенности развития институтов рыночной инфраструктуры // Региональные проблемы преобразования экономики. - № 3. - 2016. - C. 81-88.

13. Кириенко О. Э., Киященко Т. А. Управление развитием рыночной инфраструктуры региона // Государственное и муниципальное управление. Ученые записки. - 2019. - № 1. - С. 57-63.

14. Маневич В. Е., Одесс В. И., Селезнева Л. А. Рыночная инфраструктура и платежеспособный спрос в российской экономике. Лаборатория инфраструктуры рынка. ИПР РАН, 1998.

15. Митюхин Д. С. Механизм управления рыночной инфраструктурой региона // Крымский научный вестник. -2015 . - № 4. - C. 350-367.

16. Муханова Е. Б. Теоретические основы и пути формирования рыночной инфраструктуры. - М., 1994. $-162 \mathrm{c}$.

17. Шарифьянов Т. Ф. Институцฺиональное обеспечение развития региональной инфраструктурь // Региональная экономика и управление: электронный научный журнал. - 2019. - № 1 (57). [Электронный ресурс]. Режим доступа: https://eеe-region.ru/article/5704/, свободный. - Загл. с экрана.

18. Baussola M. Knowlege Spillovers and Economic Growth: Regional Growth Differentials across Europe. 2007. $132 \mathrm{p}$.

19. Laffont J. J. Incentives and political economy // Oxford University Press. 2007. 126 p.

20. Trebing H. The Networks as Infrastructure / H.Trebing // The Reestablishment of Market PowerJournal of Economic Issues June, 1994. Vol. 26. No. 2. 379 p.

\section{References:}

1. Abaev A. V. Vliyanie infrastruktury na ekonomicheskij rost v regione // Razvitie ekonomiki $i$ biznesa: sb. nauch. tr. / pod red A F. SHuplecova. - Irkutsk: Izd-vo BGUEP, 2011. - 173 s.

2. Alklychev A. M. Upravlenie processom razvitiya rynochnoj infrastruktury tovarnogo rynka: regional'nyj aspekt // Konkurentosposobnost' regionov. Strategiya ustojchivogo razvitiya: III Mezhd. nauchnoprakticheskaya konf. 2017. (Pskov, 25-27 oktyabrya 2017 g.). Pskov: Izd-vo Pskovskogo gosudarstvennogo universiteta, 2017. - S. 61-69.

3. Alklychev A. M. Innovacionnaya politika regionov Rossijskoj Federacii v celyah privlecheniya investicij $i$ vozmozhnosti ee realizacii // Regional'naya ekonomika: teoriya i praktika. - 2014. - № 3 (330). - S. 2 -9. 
АЛКЛЫЧЕВ А.М., ШОГЕНОВ Б. А., ШАКОВА Ф.М.

РЫНОЧНАЯ ИНФРАСТРУКТУРА РЕГИОНА: ВЧЕРА, СЕГОДНЯ, ЗАВТРА

4. Alklychev A. M. Investicionnyj mekhanizm finansirovaniya sel'skohozyajstvennyh predpriyatij v regione // Regional'nye problemy preobrazovaniya ekonomiki. - 2015. - № 12 (62). - S. 15-22.

5. Andreeva O. R. K voprosu o dinamike elementnogo sostava infrastruktury // Aktual'nye problemy sovremennogo hozyajstvennogo razvitiya: vosproizvodstvennyj aspekt: sb. nauch. tr. / Pod red. B. D. Babaeva. -Ivanovo: Ivan.gos. un-t, 2010. - 472 s.

6. Ahtarieva L. G. Sistemnaya modernizaciya regional'noj rynochnoj infrastruktury // Problemy sovremennoj ekonomiki. - 2008. - № 3 (27). - S. 388-393.

7. Belyaevskij I. K. Marketingovye issledovaniya: Uchebnoe posobie / Moskovskij gosudarstvennyj universitet ekonomiki, statistiki i informatiki. - M. 2004. - 414 s.

8. Biznes-plan. Pod. red. R. G. Manilovskogo. - M. Finansy i statistika. 2002. - 160 s.

9. Doholyan S. V., Vartanova M. L. Konceptual'nye osnovy effektivnogo funkcionirovaniya infrastruktury prodovol'stvennogo rynka regiona // Rossijskoe predprinimatel'stvo. - 2017. - № 10. - Tom 18. - S. 1523-1546.

10. ZHuravleva G. P. Ekonomicheskaya teoriya. Mikroekonomika - 1, 2: Uchebnik / Pod obshch. red. zasluzhennogo deyatelya nauki RF, prof., d-ra ekon. nauk G. P. ZHuravlevoj. - 6-e izd., ispr. i dop. - M.: Izdatel'sko -torgovaya korporaciya «Dashkov $i K^{\circ} », 2014$. - 934 s.

11. Zoidov K. H., Alklychev A. M. Upravlenie processom razvitiya rynochnoj infrastruktury tovarnogo rynka regiona // Finansovye mekhanizmy aciklicheskogo regulirovaniya strukturnyh disproporcij v ekonomike Rossii i drugih stran SNG: mezhd. nauchno-prakticheskaya konf. 2017. (Moskva, 26-27 fevralya 2017 g.). - M.: Izdvo Instituta problem rynka RAN, 2017. - S. 132-138.

12. Idziev G. I. Regional'nye osobennosti razvitiya institutov rynochnoj infrastruktury // Regional'nye problemy preobrazovaniya ekonomiki. - № 3. - 2016. - S. 81-88.

13. Kirienko O. E., Kiyashchenko T. A. Upravlenie razvitiem rynochnoj infrastruktury regiona // Gosudarstvennoe i municipal'noe upravlenie. Uchenye zapiski. - 2019. - № 1. - S. 57-63.

14. Manevich V. E., Odess V. I., Selezneva L. A. Rynochnaya infrastruktura i platezhesposobnyj spros $v$ rossijskoj ekonomike. Laboratoriya infrastruktury rynka. IPR RAN, 1998.

15. Mityuhin D. S. Mekhanizm upravleniya rynochnoj infrastrukturoj regiona // Krymskij nauchnyj vestnik. 2015. - № 4. - S. 350-367.

16. Muhanova E. B. Teoreticheskie osnovy i puti formirovaniya rynochnoj infrastruktury. - M., 1994. $-162 \mathrm{~s}$.

17. SHarif'yanov T. F. Institucional'noe obespechenie razvitiya regional'noj infrastruktury // Regional'naya ekonomika i upravlenie: elektronnyj nauchnyj zhurnal. - 2019. - № 1 (57). [Elektronnyj resurs]. Rezhim dostupa: https://eee-region.ru/article/5704/, svobodnyj. - Zagl. s ekrana.

18. Baussola M. Knowlege Spillovers and Economic Growth: Regional Growth Differentials across Europe. 2007. $132 \mathrm{p}$

19. Laffont J. J. Incentives and political economy // Oxford University Press. 2007. 126 p.

20. Trebing H. The Networks as Infrastructure / H.Trebing // The Reestablishment of Market PowerJournal of Economic Issues June, 1994. Vol. 26. No. 2. 379 p. 